\title{
Diffusion Ignition Processes in MILD Combustion: A Mini-Review
}

\author{
Giancarlo Sorrentino $^{1 *}$, Antonio Cavaliere ${ }^{1}$, Pino Sabia ${ }^{2}$, Raffaele Ragucci ${ }^{2}$ and \\ Mara de Joannon ${ }^{2}$
}

'Dipartimento di Ingegneria Chimica, dei Materiali e della Produzione Industriale, Università degli studi di Naples "Federico II", Naples, Italy, ${ }^{2}$ Istituto di Ricerche sulla Combustione (IRC), Consiglio Nazionale delle Ricerche (CNR), Naples, Italy

MILD combustion processes belong to new combustion technologies developed to achieve efficient and clean fuel conversion. The basic concept behind its implementation is the use of high levels of hot exhausted gas recirculation within the combustion chamber. They simultaneously dilute fresh reactants, to control system temperatures and pollutants emission, while promoting fuel complete oxidation. The combination of low maximum system working temperatures and high diluted mixtures with intense pre-heating delineates an oxidation process with unique chemical and physical features, such as uniformity of scalars at macroscale related to distributed reacting regions at microscale, extremely different from conventional flames. In turn, this requires the definition and characterization of new elementary processes, not ascribable to traditional deflagration or diffusive flame structures, which, in literature have

OPEN ACCESS

Edited by:

Nesrin Ozalp,

University of Minnesota Duluth,

United States

Reviewed by:

Jinhua Wang,

Xi'an Jiaotong University, China Christine Mounaïm-Rousselle,

University of Orléans, France

*Correspondence: Giancarlo Sorrentino g.sorrentino@unina.it

Specialty section:

This article was submitted to Thermal and Mass Transport, a section of the journal

Frontiers in Mechanical Engineering

Received: 25 October 2019 Accepted: 20 February 2020 Published: 24 March 2020

Citation:

Sorrentino G, Cavaliere A, Sabia P, Ragucci R and de Joannon M (2020) Diffusion Ignition Processes in MILD

Combustion: A Mini-Review.

Front. Mech. Eng. 6:10

doi: 10.3389/fmech.2020.00010 been identified as "diffusion ignition." The present mini-review reports on several literature characterizations of such reactive structures under steady and unsteady conditions combining evidences from numerical, experimental, and/or theoretical studies. Both premixed and non-premixed configurations were analyzed in terms of system temperature, heat release, and species distributions as key parameters to describe the intrinsic nature of such new elementary processes. Analyses were realized changing the main system external parameters (mixture pre-heating temperature, dilution level in several feeding configurations) moving from traditional to MILD conditions. Results highlighted the "distributed ignition" nature of igni-diffusive structures, with implication on the thickness of the oxidation structures in the mixture fraction space, the presence/absence of a pyrolysis region, and the correlation of the maximum heat release with the mixture stoichiometric.

\section{Keywords: MILD combustion, distributed ignition, igni-diffusion, dilution level, heat release}

\section{INTRODUCTION}

Elementary structures in combustion such as laminar diffusion layers have been characterized in the literature (Tsuji, 1982; Chao et al., 1991; Darabiha, 1992; Chen et al., 2012). Dilution and preheating of reactants pointed out some peculiarities that were examined through numerical, experimental, and theoretical studies in the last decades (de Joannon et al., 2009; Abtahizadeh et al., 2012; Sepman A. et al., 2013; Sorrentino et al., 2013). Diffusive ignition process under MILD combustion was deeply investigated (Cavaliere and de Joannon, 2004).

The relevance of such processes concerns several fields of application such as low heating value fuel oxidation (Maruta et al., 2007), destruction of VOC, or combustion in flows with internal recirculation. 
Diffusion ignition can be described in 1-D spatial conditions, but usually they are very difficult to mimic in simple experiments due to such low dimensionality. 2-D experiments where fuel jets are injected in co-flowing or cross-flowing oxidizer streams are easier to realize for diluted and preheated conditions.

Jet in hot flows configuration was used to reproduce diffusion ignition processes (Adelaide or Delft jet in hot coflow) in both the laminar (LJHC) and turbulent (JHC) cases when inlet reactant temperatures are higher than ignition ones (Medwell et al., 2007, 2009; Choi et al., 2009; Oldenhof et al., 2011; Sepman A. V. et al., 2013). In particular, methane and $\mathrm{CH}_{4} / \mathrm{H}_{2}$ blends were analyzed by Medwell et al. (2007) and Al-Noman et al. (2016), whereas Oldenhof et al. (2010) analyzed the stabilization region of natural gas mixtures burning in a hot/diluted coflow by recording the flame luminescence with an intensified high-speed camera. The spatial distributions of the hydroxyl radical $(\mathrm{OH})$, formaldehyde $\left(\mathrm{H}_{2} \mathrm{CO}\right)$, and temperature imaged by laser diagnostic techniques were obtained for ethylene flames by Medwell et al. (2008) whereas Choi and Chung (2010) investigated the autoignition characteristics of laminar lifted ethylene flames in coflow air with elevated temperature over $800 \mathrm{~K}$. Arndt et al. (2019) studied the autoignition of propane jet-in-hot coflow with high-speed $\mathrm{OH}^{*}$ chemiluminescence imaging and high-speed Rayleigh scattering for mixture fraction, temperature, and scalar dissipation rate measurements. Liquid fuels, such as ethanol (Correia Rodrigues et al., 2015; Ye et al., 2016), have been also studied in some preliminary works.

The reactive structure features that were recognized in these studies can be summarized in such points:

1. Combustion Mode Type:

- Diffusion-ignition

- Standard deflagration or diffusion flame

- Mixed-mode regimes (partially premixed).

2. Diffusion Ignition is Strongly Sensitive to Boundary Conditions More Than Standard 1-D Deflagrative/Diffusion Flame Processes.

The same type of analysis has been also performed in Jet in Hot Cross Flow configuration (Sidey and Mastorakos, 2015; Wagner et al., 2017) where fuel was injected into hot and vitiated air crossflow. Results suggested that autoignition is the dominant stabilization mechanism.

A wide numerical/theoretical characterization of ignidiffusive steady structures under MILD conditions was reported in the literature with 1-D counterflow configurations. Reactive structures were analyzed as a function of feeding configurations from several groups (de Joannon et al., 2012a,b; Zou et al., 2014; He et al., 2016).

In the following sections, the peculiarity of diffusion ignition processes will be analyzed for steady or unsteady conditions.

\section{STEADY DIFFUSION IGNITION: HDDI AND HCDI}

Distributed combustion regime occurs in technologies where dilution and preheating of reactants are used for efficient and clean energy conversion (Li et al., 2011; Khalil and Gupta, 2017; Perpignan et al., 2018). In practical systems, gas recirculation is adopted (Sorrentino et al., 2018a; Sabia et al., 2019). Low combustion temperatures and high dilution/pre-heating alter the fuel conversion with respect to traditional flames (Maruta et al., 2000; Minamoto et al., 2014; Minamoto and Swaminathan, 2015).

Elementary processes that undergo MILD combustion influence the controlling parameters (Cavaliere et al., 2016). In particular, the reactivity under stoichiometric conditions is comparable with the one related to fuel-lean or fuel-rich conditions (de Joannon et al., 2010). It follows that reactions are homogeneously distributed (Plessing et al., 1998; Özdemir and Peters, 2001).

In particular, the characterization of diffusion-controlled combustion processes developing in a steady 1-D layer was reported in the literature with several numerical studies by means of the opposed jets configuration (de Joannon et al., 2007; Cheong et al., 2017; Mameri et al., 2018).

This section takes into account numerical characterization of steady mixing layers with diluted and/or preheating streams with different feeding configurations as a function of main parameters.

In this review article, a sub-classification of steady diffusion ignition process will be used as reported in the following:

1. Reactants with homogenous mixture composition and preheating of inert flow as main controlling parameters [homogeneous charge diffusion ignition (HCDI)]

2. Non-premixed flows with reactants dilution and preheating as main controlling parameters [hot diluted diffusion ignition (HDDI)].

In the HCDI mode (de Joannon et al., 2007; Mastorakos, 2009; Goh et al., 2013), a homogeneous reactant charge interacts with inert (such as nitrogen or carbon dioxide) at high temperature (i.e., combustion products) and this yields a counter-diffusion layer. On the other hand, the HDDI is realizable for nonpremixed streams with a certain level of dilution and/or preheating (de Joannon et al., 2009; Chen and Zheng, 2011; Ye et al., 2017). The initial conditions of HCDI processes are fixed on one side of spatial coordinate homogeneous reactants in a fixed composition and the species on the other side are inert (for instance combustion products) at high temperature, as reported in the sketch of the insert in Figure 1A. As is wellknown, a premixed fuel/air mixture outside the flammability limit cannot support a deflagration process. Several experimental studies have reported the occurrence of this process when the heat source is a heated wall or a high-temperature inert flow in a laminar (Darabiha et al., 1988; Smooke et al., 1991; Zheng et al., 2002) or turbulent (Blouch et al., 1998) counterflow. In particular, Mastorakos et al. (1995) investigated the effects of simultaneous dilution and preheat of reactants by mixing with hot combustion products in turbulent counterflow flames formed near the impinging region of two opposed jets. Examples of this reactive structure are also obtained in a counterflow configuration as shown in the sketch of Figure 1A for a methane/oxygen stream that impinges toward high-temperature flows. The bulk flow velocities define the system strain rate. The sketch in Figure 1A shows the location of the reactive region (orange area) when the mixture is outside the flammability limits 


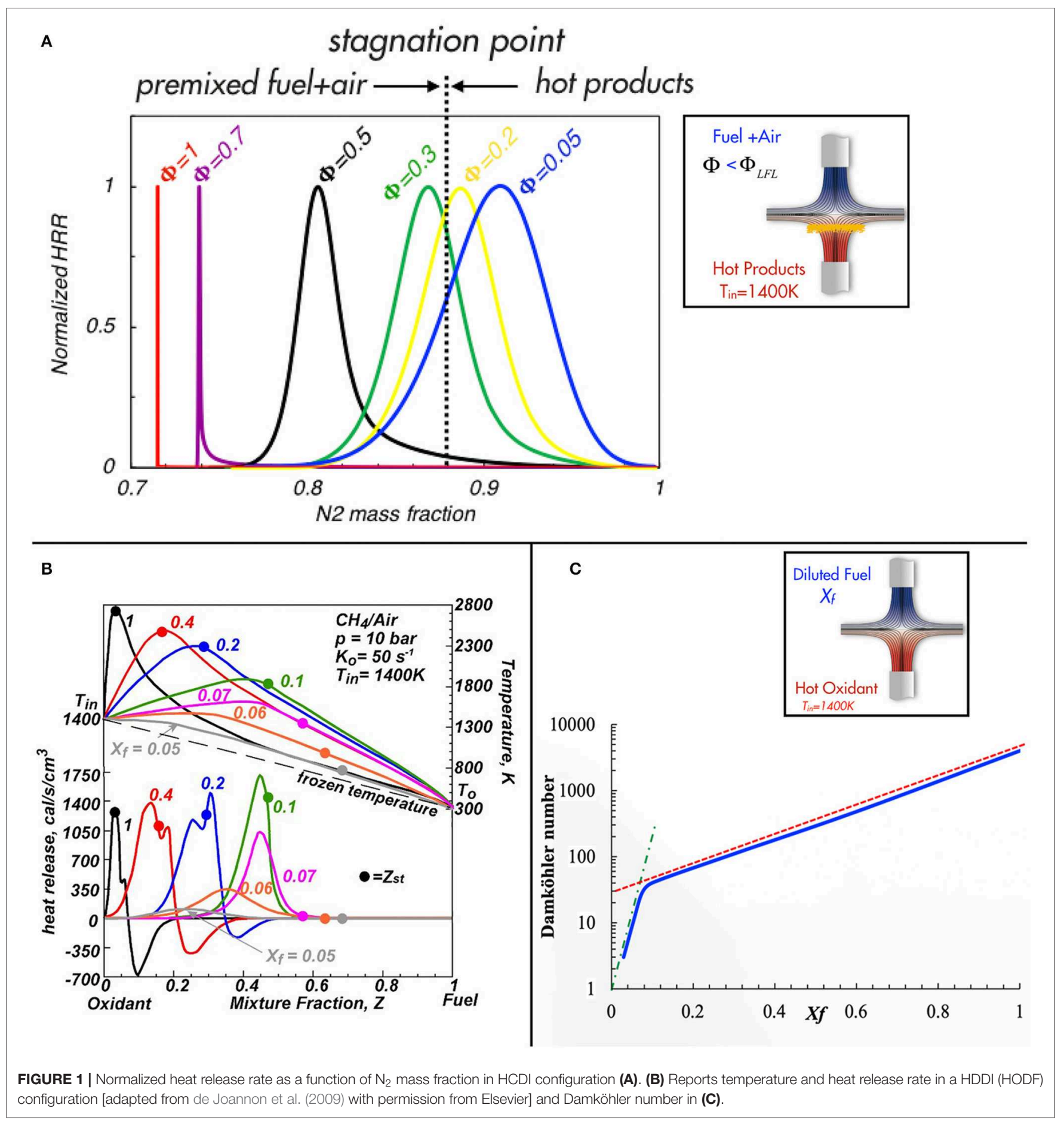

$\left(\Phi<\Phi_{\mathrm{LFL}}\right)$. Such counterflow allows for the characterization of several HCDI or deflagration structures (de Joannon et al., 2007). In particular, the results shown in Figure 1A (Cavaliere et al., 2016) reports a homogeneous fuel/air charge continuously heated by a hot inert flow of $\mathrm{N}_{2}$ (mimicking combustion products). A premixed $\mathrm{CH}_{4}$-air flow, characterized by an inlet temperature $\left(T_{0}\right)$ and velocity $\left(V_{0}\right)$, is fed toward an opposed flow of nitrogen at high temperatures $\left(T_{\text {in }}\right)$. The distance $D$ between the jets is $2 \mathrm{~cm}$. Numerical analysis was carried out by means of Oppdif application for counterflow configurations of ChemKin 3.7 package by using the GRI 3.0 mechanism as kinetics model. The enthalpy production reported in Figure 1A with a red curve at $T_{\text {in }}=1,400 \mathrm{~K}$ for $k=50 \mathrm{~s}^{-1}$ is positioned on the premixed fuel/air side for $\Phi=1$ with a very thin reactive region. By decreasing the inlet equivalence ratio, these heat release curves are different from those at $\Phi=1$ as they 
are broadened, and are shifted closer to the stagnation point. Notably, the reactive zone location passes the stagnation point for $\Phi<0.2$ when the mixture is outside the flammability limits. In this case, the oxidative structures are located on the hot products side.

In summary, the figure demonstrates that a great variety of oxidation structures may be stabilized in HCDI processes and the features of the oxidation process are related to the diffusion between the hot products and the air/fuel charge. Such behavior can be ascribed to MILD combustion and it has features that partially explain the distributed and noiseless characteristic reported for some flameless applications (Wünning and Wünning, 1997; Khidr et al., 2017; Zhou et al., 2017). In fact, the reactive process is distributed on a wide mixture fraction region and the transition from HCDI to deflagration is gradual (Sidey et al., 2014).

Combustion processes in which the reactants are separated yield diffusion flames and they can be obtained in a counterdiffusion reactor when it is fed with oxidant and fuel in opposite directions along the same axis. In MILD combustion, such streams can be diluted with inert species (such as combustion products) and can be heated to such high temperatures that the frozen temperature is higher than the ignition one (de Joannon et al., 2010; Sidey and Mastorakos, 2016).

In this case, the non-premixed configuration, as reported in the sketch of Figure 1C, is characterized by fuel at ambient temperature and molar fraction $X_{\mathrm{f}}$ that is fed vs. an opposed airflow at a fixed preheating temperature $\left(T_{\text {in }}\right)$. The flow rates are kept constant to fix the bulk strain rates $K_{0}=V_{0} / D$. In Figure 1B, the structure of the reactive zone was depicted for HODF where temperature and heat release rate profiles as a function of the mixture fraction $(Z)$ were reported for several $X_{\mathrm{f}}$ values. The plots of Figure 1B (adapted by de Joannon et al., 2009) were obtained at $P=10$ bar for a $\mathrm{CH}_{4} /$ Air system. They refer to diluted methane at ambient temperature diffusing in hot air at $T_{\text {in }}=1,400 \mathrm{~K}$, i.e., a HODF (Hot Oxidant Diluted Fuel) feeding in a SICF (Steady Igniting Counter-Flow). Numerical tools and kinetics mechanisms are the same used for HCDI cases reported before. Methane content was varied from $X_{\mathrm{f}}=1$ to 0.05 by means of $\mathrm{N}_{2}$ dilution. The stoichiometric mixture fraction location is indicated on the profiles with dots. The heat release profile (lower part of Figure 1B) reported with the black curve is related to an undiluted case and it exhibits a maximum in correspondence of $Z_{\text {st }}$ whereas pyrolytic regions with negative heat release occur for fuel-rich region. A similar behavior was obtained for $T$ (upper part) that reaches a maximum value of about $2,800 \mathrm{~K}$. The fuel dilution strongly alters the oxidative structure as a function of its magnitude and it emphasizes the difference with respect to conventional conditions. For $X_{\mathrm{f}}=0.5$, the $T_{\max }$ values are shifted toward higher $Z$ and the oxidation region in the heat release profile shifts and widens. The pyrolytic region is enlarged toward higher $Z$ with strong reduction of the minimum heat release rate. This behavior becomes more clear by decreasing $X_{\mathrm{f}}$, causing the vanishing of the pyrolytic region for dilution level higher than $85 \%$. In fact, when the dilution level reaches $90 \%\left(X_{\mathrm{f}}=0.1\right)$, heat release profiles exhibit only a single maximum that diminishes its intensity with $X_{\mathrm{f}}$. Moreover, the most important effect of the dilution is a shift of the oxidative region backward toward lower $Z$, in opposite direction with the stoichiometry (as reported by the colored dots that indicate the $Z_{\text {st }}$ location).

Therefore, by summarizing, several peculiar characteristics have been pointed out as discriminative for the occurrence of different combustion regimes. They have been related to reactive region thickness, absence of a pyrolysis region, and the correlation of the maximum heat release with the $Z_{\mathrm{st}}$. Following such criteria, the features of the reaction zone suggested a different name for the elementary process with respect to standard diffusion ones, and thus, HDDI was chosen for such non-premixed case.

The results above reported revealed that both the HDDI and HCDI modes support a "distributed ignition" behavior. Moreover, a strong extinction resilience was also reported in several literature papers as another important feature of such MILD processes (Sidey et al., 2016; Evans et al., 2017; Sidey and Mastorakos, 2018). All these features are linked to each other.

Another important synthetic representation of MILD features is reported with the blue curve in Figure 1C where Damköhler number is reported vs. the fuel mole fraction. Its evaluation is based on the ratio between a characteristic convective time (based on the strain rate) and a kinetic one. More specifically, it diminishes from about 7,000 to 50 by decreasing the $X_{\mathrm{f}}$ value from 1 to 0.1 . Also, in this case, the most relevant variation is shown at $90 \%$ fuel dilution where Da undergoes a significant change. This is correlated to a "gradual" behavior of the reactive process that entails a continuous increase of chemical kinetics times with respect to a reference fluid-dynamic one. It is of interest that the Damköhler number change is three orders of magnitude with respect to undiluted cases. In particular, two asymptotic behaviors can be identified with the dashed red line for $0.15<X_{\mathrm{f}}<1$ and with the dashed-dotted green one for $X_{\mathrm{f}}<0.1$. Such paradigm shift in the reactive structures at a fixed dilution level was also identified in several literature papers for diluted conditions in SICF (Fotache et al., 1997, 1998; Abtahizadeh et al., 2012) and confirmed also for low-heating value fuels (Kwiatkowski and Mastorakos, 2016).

\section{UNSTEADY DIFFUSION IGNITION}

Igni-diffusive structure characterizations are possible in 1-D configurations by following the temporal evolution of diffusion layer ignition/oxidation for diluted and preheated conditions in wide parameter ranges. In this case, unsteady elementary processes strongly depend on the boundary conditions and fluid-dynamics pattern. In particular, literature evidenced two main possibilities for transient diffusion-controlled combustion processes in 1-D configurations: IML (Igniting Mixing Layer) and ICF (Igniting Counter-Flow).

IML can be defined as a "universal" or "zero-order" configuration because it represents the natural evolution of diffusive-reactive process (Abtahizadeh et al., 2015). Therefore, it is of interest as reference case because the temporal evolution refers to an initial unmixed mixture where the initial mixture fraction gradient is not prescribed by a fixed strain rate 


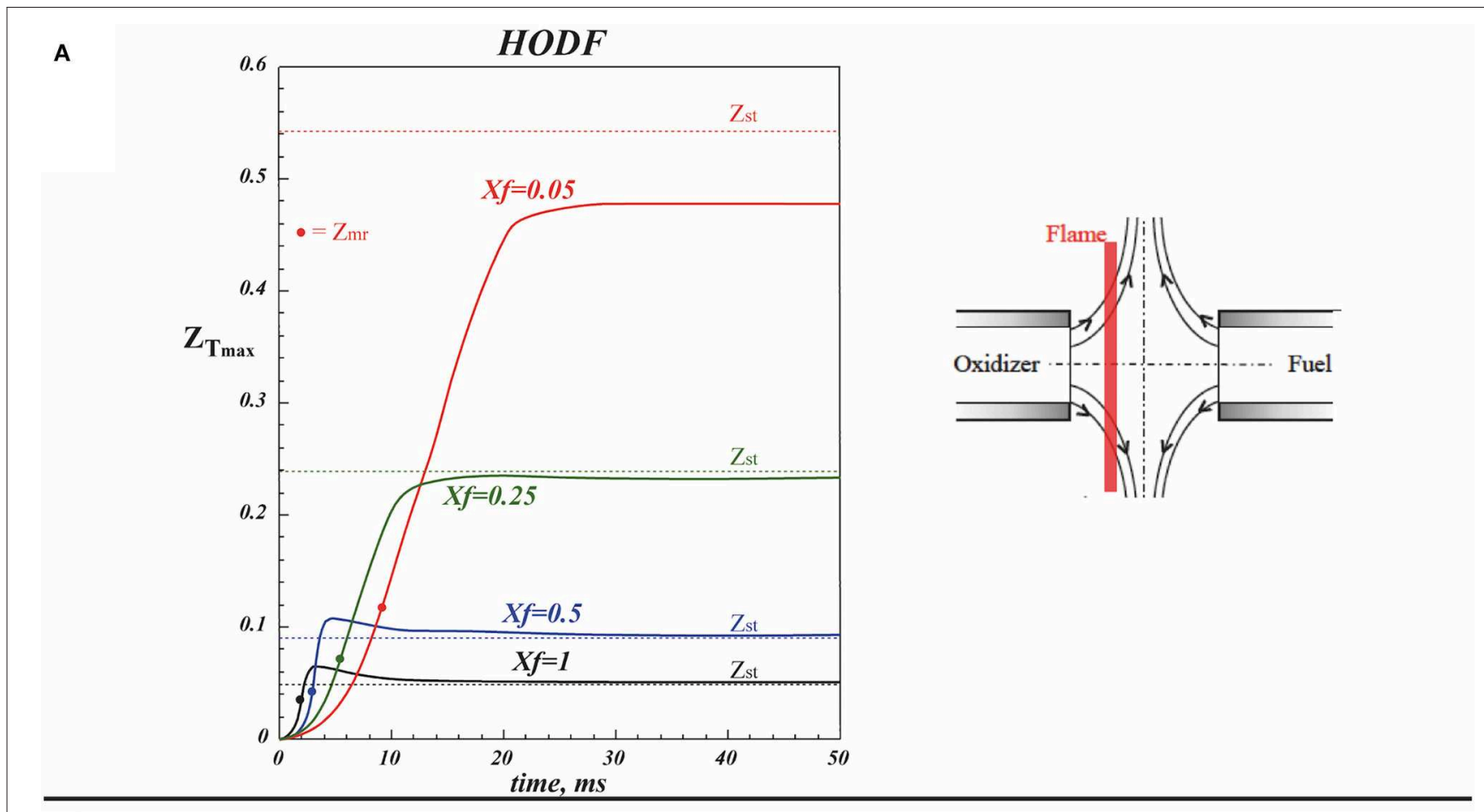

B

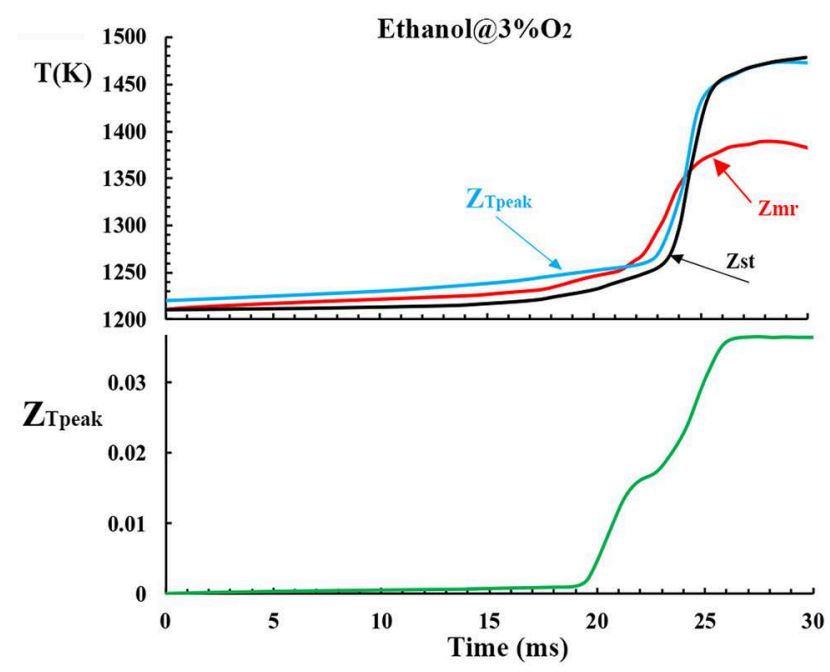

Transient Ignition for Jet in Hot Coflow

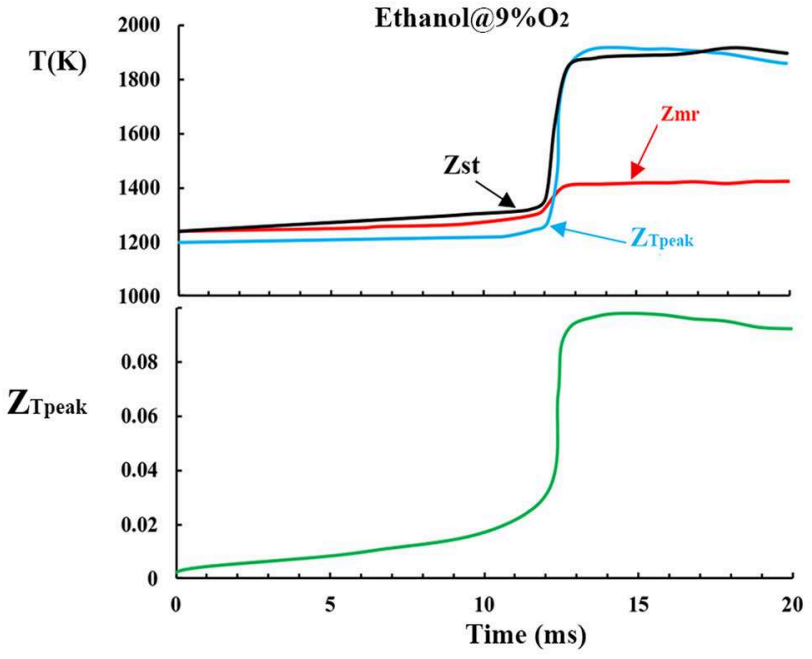

FIGURE 2 | Temporal evolution of mixture fraction where the peak temperature occurs for HODF conditions (A) adapted from Sorrentino et al. (2013) with permission from Elsevier. (B) Reports transient numerical computations for ethanol in JHC flames with the boundary conditions obtained from the experiments by Ye et al. (2018). Temperature and $Z_{\text {Tpeak }}$ as a function of time were reported for two oxygen levels.

but is controlled by molecular diffusion. It is a key process also for inferring tabulated chemistry information for complex systems (Sorrentino et al., 2018b). IML was reported in the literature to evaluate ignition characteristics (most reactive mixture fraction) of diluted fuels in comparison with AutoIgnition and Homogeneous Ignition (Mastorakos et al., 1997; Im et al., 1998; Sreedhara and Lakshmisha, 2000; Hilbert and Thévenin, 2002; van Oijen, 2013).
ICF in steady strain flow field is the configuration in which the transient diffusion ignition process evolves in a developed mixing layer originated by a mixture fraction in two opposed laminar jets, where the initial mixture fraction is distributed according to frozen mixing due to applied strain. This kind of process was one of the most characterized in the literature because it can be obtained through coflow configurations for both the undiluted and diluted cases, as already underlined in the Introduction 
section (Cabra et al., 2002; Dally et al., 2002; Chung, 2007). In this case, several regimes such as autoignition, flame propagation, and diffusion ignition can occur (Medwell et al., 2016; Schulz et al., 2017).

Unsteady 1-D reactive diffusive layer evolution has been depicted for HODF conditions in Figure 2A by reporting the numerical results obtained in ICF configuration and adapted by the results of Sorrentino et al. (2013).

The profiles in Figure 2A show the temporal evolution of the maximum temperature location in the mixture fraction space. The solid dots depict the location of the most reactive mixture fraction $\left(Z_{\mathrm{mr}}\right)$ whereas the dashed lines are related to the position of $Z_{\text {st }}$. It is worthwhile to note that, for undiluted or slightly diluted conditions $\left(0.2<X_{\mathrm{f}}<1\right)$, the location of $Z_{\mathrm{mr}}$ and $Z_{\mathrm{st}}$ is very close to each other. It means that ignition and stabilization phenomena occur in the same mixture fraction and time intervals (Im et al., 2000). Therefore, in such cases, the diffusive structure growth in time is limited to a narrow mixture fraction space. For $X_{\mathrm{f}}<0.1$, the main effect of MILD combustion (because the reactant dilution slows down the oxidative chemical kinetics) is to increase the distance between the "most reactive" mixture fraction and the "stoichiometric" one. In each case, the most reactive mixture fraction is always placed on the high-temperature side (preheated oxidizer in Figure 2A) and the location is not affected by dilution (Viggiano and Magi, 2004; Yoo et al., 2011).

The aforementioned behaviors were confirmed for ethanoldiluted flames in JHC configuration, as reported in the numerical results of Figure 2B, where boundary conditions were obtained from Ye et al. (2018). Unsteady flamelet equations were solved in time and mixture fraction space using the FlameMaster program (Pitsch, 1998). It shows the peak temperature as a function of time for ethanol at 3 and $9 \%$ of $\mathrm{O}_{2}$. The mixture fraction where the peak temperature occurs is denoted as $Z_{\text {Tpeak. }}$. As the oxygen level reduces from 9 to $3 \%$, the ignition process becomes prolonged with a reduced temperature increase. Thus, flames in the $3 \% \mathrm{O}_{2}$ case are close to diffusion ignition cases, being distributed with a low temperature increase.

Recent DNS studies (Doan et al., 2018) confirmed the importance of dilution and $Z_{\mathrm{mr}}$ location on the stabilization but they also depicted that non-premixed turbulent MILD combustion is a complex process with spatial and temporal ignition fronts, non-premixed, and propagating flames that are strongly convoluted and interacting. In particular, multiple igniting mixing layers can interact between themselves and the

\section{REFERENCES}

Abtahizadeh, E., de Goey, P., and van Oijen, J. (2015). Development of a novel flamelet-based model to include preferential diffusion effects in autoignition of $\mathrm{CH}_{4} / \mathrm{H}_{2}$ flames. Combust. Flame 162, 4358-4369. doi: 10.1016/j.combustflame.2015.06.015

Abtahizadeh, E., van Oijen, J., and de Goey, P. (2012). Numerical study of Mild combustion with entrainment of burned gas into oxidizer and/or fuel streams. Combust. Flame 159, 2155-2165. doi: 10.1016/j.combustflame.2012.02.004 annihilation of peripheral isolines may strongly influence the reactive structures (Sorrentino et al., 2017).

\section{CONCLUSIVE REMARKS}

The analyses reported so far have emphasized that the occurrence of MILD combustion in diffusion-controlled conditions strongly differs from deflagration and diffusion flames. These characteristics are of interest in comparison to the conventional flame structure where the mixture fraction range in which the reaction takes place is quite narrow and changes slightly with dissipation rate. In contrast, the oxidation structure of MILD combustion shifts along the mixture fraction space according to different boundary conditions (temperature and dilution). The features of diffusion ignition are related to several peculiarities such as distributed ignition, flameless oxidation, and heat release not correlated with stoichiometric mixture fraction, differently from flame structured processes.

Strong extinction resilience and gradual ignition are also distinctive characteristics of such reactive structures that were highlighted by analyzing the unsteady evolution of the diffusive reactive layer under preheated and diluted conditions.

\section{AUTHOR CONTRIBUTIONS}

GS and PS were involved in the bibliographic research to include in the manuscript the most important literature contributions on the diffusion ignition process in MILD combustion. They have also strongly contributed in writing several parts of the article. AC and MJ gave their support in the theoretical background regarding categorization and classification of MILD combustion processes. RR gave important insights and hints in the physical description of diffusion ignition and its connection with dimensionless numbers. He also strongly revised the English language in the manuscript.

\section{FUNDING}

This work was financially supported with funding of the MSECNR project 2013-2014 Miglioramento dell'efficienza energetica dei sistemi di conversione locale di energia.

\section{ACKNOWLEDGMENTS}

This article is based upon work from COST Action SMARTCATs (CM1404), supported by COST (European Cooperation in Science and Technology, http://www.cost.eu).

Al-Noman, S., Choi, S. K., and Chung, S. H. (2016). Numerical study of laminar nonpremixed methane flames in coflow jets: autoignited lifted flames with tribrachial edges and MILD combustion at elevated temperatures. Combust. Flame 171, 119-132. doi: 10.1016/j.combustflame.2016. 06.021

Arndt, C. M., Papageorge, M. J., Fuest, F., Sutton, J. A., and Meier, W. (2019). Experimental investigation of the auto-ignition of a transient propane Jet-in-Hot-Coflow. Proc. Combust. Inst. 37, 2117-2124. doi: 10.1016/j.proci.2018.06.195 
Blouch, J. D., Sung, C. J., Fotache, C. G., and Law, C. K. (1998). Turbulent ignition of non-premixed hydrogen by heated counterflowing atmospheric air. Symposium on Combust. 27, 1221-1228. doi: 10.1016/S0082-0784(98)80526-2

Cabra, R., Myhrvold, T., Chen, J. Y., Dibble, R. W., Karpetis, A. N., and Barlow, R. S. (2002). Simultaneous laser raman-rayleigh-lif measurements and numerical modeling results of a lifted turbulent $\mathrm{H}_{2} / \mathrm{N}_{2}$ jet flame in a vitiated coflow. Proc. Combust. Inst. 29, 1881-1888. doi: 10.1016/S1540-7489(02)80228-0

Cavaliere, A., and de Joannon, M. (2004). Mild combustion. Prog. Energy Combust. Sci. 30, 329-366. doi: 10.1016/j.pecs.2004.02.003

Cavaliere, A., de Joannon, M., Sabia, P., Sorrentino, G., and Ragucci, R. (2016). "Highly preheated lean combustion," in Lean Combustion: Technology and Control, 2nd Edn, Vol. 3, eds D. Dunn-Rankin and P. Therkelsen (London: Imprint by Academic Press), 63-105. doi: 10.1016/B978-0-12-804557-2.00003-1

Chao, B. H., Law, C. K., and T'ien, J. S. (1991). Structure and extinction of diffusion flames with flame radiation. Symp. Combust. 23, 523-531. doi: 10.1016/S0082-0784(06)80299-7

Chen, S., Mi, J., Liu, H., and Zheng, C. (2012). First and second thermodynamiclaw analyses of hydrogen-air counter-flow diffusion combustion in various combustion modes. Int. J. Hydrogen Energy 37, 5234-5245. doi: 10.1016/j.ijhydene.2011.12.039

Chen, S., and Zheng, C. (2011). Counterflow diffusion flame of hydrogen-enriched biogas under MILD oxy-fuel condition. Int. J. Hydr. Energy 36, 15403-15413. doi: 10.1016/j.ijhydene.2011.09.002

Cheong, K. P., Li, P., Wang, F., and Mi, J. (2017). Emissions of NO and CO from counterflow combustion of $\mathrm{CH} 4$ under MILD and oxyfuel conditions. Energy 124, 652-664. doi: 10.1016/j.energy.2017.02.083

Choi, B. C., and Chung, S. H. (2010). Autoignited laminar lifted flames of methane, ethylene, ethane, and n-butane jets in coflow air with elevated temperature. Combust. Flame 157, 2348-2356, doi: 10.1016/j.combustflame.2010. 06.011

Choi, B. C., Kim, K. N., and Chung, S. H. (2009). Autoignited laminar lifted flames of propane in coflow jets with tribrachial edge and mild combustion. Combustion Flame 156, 396-404, doi: 10.1016/j.combustflame.2008. 10.020

Chung, S. H. (2007). Stabilization, propagation and instability of tribrachial triple flames. Proc. Combustion Inst. 31, 877-892. doi: 10.1016/j.proci.2006.08.117

Correia Rodrigues, H., Tummers, M. J., van Veen, E. H., and Roekaerts, D. J. E. M. (2015). Effects of coflow temperature and composition on ethanol spray flames in hot-diluted coflow. Int. J. Heat Fluid Flow 51, 309-323. doi: 10.1016/j.ijheatfluidflow.2014.10.006

Dally, B. B., Karpetis, A. N., and Barlow, R. S. (2002). Structure of turbulent non-premixed jet flames in a diluted hot coflow. Proc. Combustion Inst. 29, 1147-1154. doi: 10.1016/S1540-7489(02)80145-6

Darabiha, N. (1992). Transient behaviour of laminar counterflow hydrogen-air diffusion flames with complex chemistry. Combust. Sci. Technol. 86, 163-181. doi: 10.1080/00102209208947193

Darabiha, N., Candel, S. M., Giovangigli, V., and Smooke, M. D. (1988). Extinction of strained premixed propane-air flames with complex chemistry. Combust. Sci. Tech. 60, 267-285. doi: 10.1080/00102208808923988

de Joannon, M., Matarazzo, A., Sabia, P., and Cavaliere, A. (2007). Mild combustion in homogeneous charge diffusion ignition (HCDI) regime. Proc. Combust. Inst. 31, 3409-3416. doi: 10.1016/j.proci.2006.07.039

de Joannon, M., Sabia, P., and Cavaliere, A. (2010). "Mild Combustion" in Handbook of Combustion, Vol. 5, New Technologies, eds M. Lackner, F. Winter, A. K. Agarwal (Weinheim: Wiley-VCH Verlag), 237-255. doi: 10.1002/9783527628148.hoc081

de Joannon, M., Sabia, P., Cozzolino, G., Sorrentino, G., and Cavaliere, A. (2012a). Pyrolitic and oxidative structures in hot oxidant diluted oxidant (HODO) MILD combustion. Combust. Sci. Tech. 184, 1207-1218. doi: 10.1080/00102202.2012.664012

de Joannon, M., Sabia, P., Sorrentino, G., and Cavaliere, A. (2009). Numerical study of mild combustion in hot diluted diffusion ignition (HDDI) regime. Proc. Combust. Inst. 32, 3147-3154. doi: 10.1016/j.proci.2008. 09.003

de Joannon, M., Sorrentino, G., and Cavaliere, A. (2012b). MILD combustion in diffusion-controlled regimes of Hot Diluted Fuel. Combust. Flame 159, 1832-1839. doi: 10.1016/j.combustflame.2012.01.013
Doan, N. A. K., Swaminathan, N., and Minamoto, Y. (2018). DNS of MILD combustion with mixture fraction variations. Combust. Flame 189, 173-189. doi: 10.1016/j.combustflame.2017.10.030

Evans, M. J., Chinnici, A., Medwell, P. R., and Ye, J. (2017). Ignition features of methane and ethylene fuel-blends in hot and diluted coflows. Fuel 203, 279-289. doi: 10.1016/j.fuel.2017.04.113

Fotache, C. G., Kreutz, T. G., and Law, C. K. (1997). Ignition of counterflowing methane versus heated air under reduced and elevated pressures. Combust. Flame 108, 442-470. doi: 10.1016/S0010-2180(97)81404-6

Fotache, C. G., Sung, C. J., Sun, C. J., and Law, C. K. (1998). Mild oxidation regimes and multiple criticality in nonpremixed hydrogen-air counterflow. Combust. Flame 112, 457-471. doi: 10.1016/S0010-2180(97)00132-6

Goh, K. H. H., Geipel, P., Hampp, F., and Lindstedt, R. P. (2013). Regime transition from premixed to flameless oxidation in turbulent JP-10 flames. Proc. Combust. Inst. 34, 3311-3318. doi: 10.1016/j.proci.2012.06.173

He, Y., Zou, C., Song, Y., Liu, Y., and Zheng, C. (2016). Numerical study of characteristics on NO formation in methane MILD combustion with simultaneously hot and diluted oxidant and fuel (HDO/HDF). Energy 112, 1024-1035. doi: 10.1016/j.energy.2016.07.020

Hilbert, R., and Thévenin, D. (2002). Autoignition of turbulent non-premixed flames investigated using direct numerical simulations. Combust. Flame 128, 22-37. doi: 10.1016/S0010-2180(01)00330-3

Im, H. G., Chen, J. H., and Law, C. K. (1998). Ignition of hydrogenair mixing layer in turbulent flows. Symp. Combust. 27, 1047-1056. doi: 10.1016/S0082-0784(98)80505-5

Im, H. G., Raja, L. L., Kee, R. J., and Petzold, L. R. (2000). A numerical study of transient ignition in a counterflow nonpremixed methane-air flame using adaptive time integration. Combust. Sci. Tech. 158, 341-363. doi: 10.1080/00102200008947340

Khalil, A. E. E., and Gupta, A. K. (2017). Towards colorless distributed combustion regime. Fuel 195, 113-122. doi: 10.1016/j.fuel.2016.12.093

Khidr, K. I., Eldrainy, Y. A., and Kassaby, E. L. (2017). Towards lower gas turbine emissions: flameless distributed combustion. Renew. Sustain. Energy Rev. 67, 1237-1266. doi: 10.1016/j.rser.2016.09.032

Kwiatkowski, K., and Mastorakos, E. (2016). Regimes of nonpremixed combustion of hot low-calorific-value gases derived from biomass gasification. Energy Fuels 30, 4386-4397. doi: 10.1021/acs.energyfuels.5b02580

Li, P. F., Mi, J. C., Dally, B. B., Wang, F. F., Wang, L., Liu, Z. H., et al. (2011). Progress and recent trend in MILD combustion. Sci. China Technol. Sci. 54, 255-269. doi: 10.1007/s11431-010-4257-0

Mameri, A., Tabet, F., and Hadef, A. (2018). MILD combustion of hydrogenated biogas under several operating conditions in an opposed jet configuration. Int. J. Hydrogen Energy 43, 3566-3576. doi: 10.1016/j.ijhydene.2017.04.273

Maruta, K., Abe, K., Hasegawa, S., Maruyama, S., and Sato, J. N. I. (2007) Extinction characteristics of $\mathrm{CH} 4 / \mathrm{CO} 2$ versus $\mathrm{O} 2$ /CO 2 counterflow nonpremixed flames at elevated pressures up to $0.7 \mathrm{MPa}$. Proc. Combust. Inst. 31, 1223-1230. doi: 10.1016/j.proci.2006.08.013

Maruta, K., Muso, K., Takeda, K., and Niioka, T. (2000). Reaction zone structure in flameless combustion. Proc. Combust. Inst. 28, 2117-2123. doi: 10.1016/S0082-0784(00)80621-9

Mastorakos, E. (2009). Ignition of turbulent non-premixed flames. Prog. Energy Combust. Sci. 35, 57-97. doi: 10.1016/j.pecs.2008.07.002

Mastorakos, E., Baritaud, T. A., and Poinsot, T. J. (1997). Numerical simulations of autoignition in turbulent mixing flows. Combust. Flame 109, 198-223. doi: 10.1016/S0010-2180(96)00149-6

Mastorakos, E., Taylor, A. M. K. P., and Whitelaw, J. H. (1995). Extinction of turbulent counterflow flames with reactants diluted by hot products. Combust. Flame 102, 101-114. doi: 10.1016/0010-2180(94)00252-N

Medwell, P. R., Evans, M. J., Chan, Q. N., and Katta, V. R. (2016). Laminar flame calculations for analyzing trends in autoignitive jet flames in a hot and vitiated coflow. Energy Fuels 30, 8680-8690. doi: 10.1021/acs.energyfuels.6b01264

Medwell, P. R., Kalt, P. A. M., and Dally, B. B. (2007). Simultaneous imaging of $\mathrm{OH}$, formaldehyde, and temperature of turbulent nonpremixed jet flames in a heated and diluted coflow. Combust. Flame 148, 48-61. doi: 10.1016/j.combustflame.2006.10.002

Medwell, P. R., Kalt, P. A. M., and Dally, B. B. (2008). Imaging of diluted turbulent ethylene flames stabilized on a Jet in Hot Coflow (JHC) burner. Combust. Flame 152, 100-113. doi: 10.1016/j.combustflame.2007.09.003 
Medwell, P. R., Kalt, P. A. M., and Dally, B. B. (2009). Reaction zone weakening effects under hot and diluted oxidant stream conditions. Combust. Sci. Tech. 181, 937-953. doi: 10.1080/00102200902904138

Minamoto, Y., and Swaminathan, N. (2015). Subgrid scale modelling for MILD combustion. Proc. Combust. Inst. 35, 3529-3536. doi: 10.1016/j.proci.2014.07.025

Minamoto, Y., Swaminathan, N., Cant, R. S., and Leung, T. (2014). Reaction zones and their structure in MILD combustion. Combust. Sci. Tech. 186, 1075-1096. doi: 10.1080/00102202.2014.902814

Oldenhof, E., Tummers, M. J., van Veen, E. H., and Roekaerts, D. J. E. M. (2010). Ignition kernel formation and lift-off behaviour of jet-in-hot-coflow flames. Combust. Flame 157, 1167-1178. doi: 10.1016/j.combustflame.2010.01.002

Oldenhof, E., Tummers, M. J., van Veen, E. H., and Roekaerts, D. J. E. M. (2011). Role of entrainment in the stabilisation of jet-in-hot-coflow flames. Combust. Flame 158, 1553-1563. doi: 10.1016/j.combustflame.2010.12.018

Özdemir, I. B., and Peters, N. (2001). Characteristics of the reaction zone in a combustor operating at mild combustion. Exper. Fluids 30, 683-695. doi: $10.1007 /$ s003480000248

Perpignan, A. A. V., Gangoli Rao, A., and Roekaerts, D. J. E. M. (2018). Flameless combustion and its potential towards gas turbines. Progr. Energy Combust. Sci. 69, 28-62. doi: 10.1016/j.pecs.2018.06.002

Pitsch, H. (1998). A C++ Computer Program for 0-D and 1-D Laminar Flame Calculations. Aachen: RWTH.

Plessing, T., Peters, N., and Wünning, J. G. (1998). Laseroptical investigation of highly preheated combustion with strong exhaust gas recirculation. in Symposium (International) on Combustion. Vol. 27, No. 2, pp. 3197-3204, Elsevier. doi: 10.1016/S0082-0784(98)80183-5

Sabia, P., Sorrentino, G., Bozza, P., Ceriello, G., Ragucci, R., and de Joannon, M. (2019). Fuel and thermal load flexibility of a MILD burner. Proc. Combust. Inst. 37, 4547-4554. doi: 10.1016/j.proci.2018.09.003

Schulz, O., Jaravel, T., Poinsot, T., Cuenot, B., and Noiray, N. (2017). A criterion to distinguish autoignition and propagation applied to a lifted methane-air jet flame. Proc. Combust. Inst. 36, 1637-1644. doi: 10.1016/j.proci.2016.08.022

Sepman, A., Abtahizadeh, E., Mokhov, A., van Oijen, J., Levinsky, H., and de Goey, P. (2013). Experimental and numerical studies of the effects of hydrogen addition on the structure of a laminar methane-nitrogen jet in hot coflow under MILD conditions. Int. J. Hydrogen Energy 38, 13802-13811. doi: 10.1016/j.ijhydene.2013.08.015

Sepman, A. V., Mokhov, A. V., and Levinsky, H. B. (2013). Spatial structure and NO formation of a laminar methane-nitrogen jet in hot coflow under MILD conditions: a spontaneous Raman and LIF study. Fuel 103, 705-710. doi: 10.1016/j.fuel.2012.10.010

Sidey, J., and Mastorakos, E. (2015). Visualization of MILD combustion from jets in cross-flow. Proc. Combust. Inst. 35, 3537-3545. doi: 10.1016/j.proci.2014. 07.028

Sidey, J., Mastorakos, E., and Gordon, R. L. (2014). Simulations of autoignition and laminar premixed flames in methane/air mixtures diluted with hot products. Combust. Sci. Tech. 186, 453-465. doi: 10.1080/00102202.2014.883217

Sidey, J. A. M., Giusti, A., and Mastorakos, E. (2016). Simulations of laminar non-premixed flames of kerosene with hot combustion products as oxidiser. Combust. Theory Model. 20, 958-973. doi: 10.1080/13647830.2016.1201146

Sidey, J. A. M., and Mastorakos, E. (2016). Simulations of laminar non-premixed flames of methane with hot combustion products as oxidiser. Combust. Flame 163, 1-11. doi: 10.1016/j.combustflame.2015.07.034

Sidey, J. A. M., and Mastorakos, E. (2018). Pre-chamber ignition mechanism: simulations of transient autoignition in a mixing layer between reactants and partially-burnt products. Flow Turbulence Combust. 101, 1093-1102. doi: 10.1007/s10494-018-9960-0

Smooke, M. D., Crump, J., Seshadri, K., and Giovangigli, V. (1991). Comparison between experimental measurements and numerical calculations of the structure of counterflow, diluted, methane-air, premixed flames. Symp. Combust. 23, 463-470. doi: 10.1016/S0082-0784(06)80292-4

Sorrentino, G., Ceriello, G., de Joannon, M., Sabia, P., Ragucci, R., van Oijen, J., et al. (2018b). Numerical investigation of moderate or intense low-oxygen dilution combustion in a cyclonic burner using a flamelet-generated manifold approach. Energy Fuels 32, 10242-10255. doi: 10.1021/acs.energyfuels.8b 01099
Sorrentino, G., de Joannon, M., Sabia, P., Ragucci, R., and Cavaliere, A. (2017). Numerical investigation of the ignition and annihilation of $\mathrm{CH} 4 / \mathrm{N} 2 / \mathrm{O} 2$ mixtures under MILD operative conditions with detailed chemistry. Combust. Theory Model. 21, 120-136. doi: 10.1080/13647830.2016.12 20624

Sorrentino, G., Sabia, P., de Joannon, M., Bozza, P., and Ragucci, R. (2018a). Influence of preheating and thermal power on cyclonic burner characteristics under mild combustion. Fuel 233, 207-214. doi: 10.1016/j.fuel.2018. 06.049

Sorrentino, G., Scarpa, D., and Cavaliere, A. (2013). Transient inception of MILD combustion in hot diluted diffusion ignition (HDDI) regime: a numerical study. Proc. Combust. Inst. 34, 3239-3247. doi: 10.1016/j.proci.2012. 08.002

Sreedhara, S., and Lakshmisha, K. N. (2000). Direct numerical simulation of autoignition in a non-premixed, turbulent medium. Proc. Combust. Inst. 28, 25-33. doi: 10.1016/S0082-0784(00)80191-5

Tsuji, H. (1982). Counterflow diffusion flames. Prog. Energy Combust. Sci. 8, 93-119. doi: 10.1016/0360-1285(82)90015-6

van Oijen, J. A. (2013). Direct numerical simulation of autoigniting mixing layers in MILD combustion. Proc. Combust. Inst. 34, 1163-1171. doi: $10.1016 /$ j.proci.2012.05.070

Viggiano, A., and Magi, V. (2004). A 2-D investigation of n-heptane autoignition by means of direct numerical simulation. Combust. Flame 137, 432-443. doi: 10.1016/j.combustflame.2004.03.003

Wagner, J. A., Grib, S. W., Dayton, J. W., Renfro, M. W., and Cetegen, B. M. (2017). Flame stabilization analysis of a premixed reacting jet in vitiated crossflow. Proc. Combust. Inst. 36, 3763-3771. doi: 10.1016/j.proci.2016.07.020

Wünning, J. A., and Wünning, J. G. (1997). Flameless oxidation to reduce thermal no-formation. Prog. Energy Combust. Sci. 23, 81-94. doi: 10.1016/S0360-1285(97)00006-3

Ye, J., Medwell, P. R., Dally, B. B., and Evans, M. J. (2016). The transition of ethanol flames from conventional to MILD combustion. Combust. Flame 171, 173-184. doi: 10.1016/j.combustflame.2016.05.020

Ye, J., Medwell, P. R., Evans, M. J., and Dally, B. B. (2017). Characteristics of turbulent $\mathrm{n}$-heptane jet flames in a hot and diluted coflow. Combust. Flame 183, 330-342. doi: 10.1016/j.combustflame.2017.05.027

Ye, J., Medwell, P. R., Kleinheinz, K., Evans, M. J., Dally, B. B., and Pitsch, H. G. (2018). Structural differences of ethanol and DME jet flames in a hot diluted coflow. Combust. Flame 192, 473-494. doi: 10.1016/j.combustflame.2018.02.025

Yoo, C. S., Richardson, E. S., Sankaran, R., and Chen, J. H. (2011). A DNS study on the stabilization mechanism of a turbulent lifted ethylene jet flame in highly-heated coflow. Proc. Combust. Inst. 33, 1619-1627. doi: 10.1016/j.proci.2010.06.147

Zheng, X. L., Blouch, J. D., Zhu, D. L., Kreutz, T. G., and Law, C. K. (2002). Ignition of premixed hydrogen/air by heated counterflow. Proc. Combust. Inst. 29, 1637-1643. doi: 10.1016/S1540-7489(02)80201-2

Zhou, B., Costa, M., Li, Z., Aldén, M., and Bai, X. S. (2017). Characterization of the reaction zone structures in a laboratory combustor using optical diagnostics: from flame to flameless combustion. Proc. Combust. Inst. 36, 4305-4312. doi: 10.1016/j.proci.2016.06.182

Zou, C., Cao, S., Song, Y., He, Y., Guo, F., and Zheng, C. (2014). Characteristics and mechanistic analysis of CO formation in MILD regime with simultaneously diluted and preheated oxidant and fuel. Fuel 130, 10-18. doi: 10.1016/j.fuel.2014.04.004

Conflict of Interest: The authors declare that the research was conducted in the absence of any commercial or financial relationships that could be construed as a potential conflict of interest.

Copyright (c) 2020 Sorrentino, Cavaliere, Sabia, Ragucci and de Joannon. This is an open-access article distributed under the terms of the Creative Commons Attribution License (CC BY). The use, distribution or reproduction in other forums is permitted, provided the original author(s) and the copyright owner(s) are credited and that the original publication in this journal is cited, in accordance with accepted academic practice. No use, distribution or reproduction is permitted which does not comply with these terms. 